\title{
The value of ischemia-modified albumin compared with d-dimer in the diagnosis of pulmonary embolism
} Suleyman Turedi*1, Abdulkadir Gunduz ${ }^{1}$, Ahmet Mentese2, Murat Topbas 3 , Suleyman C Karahan ${ }^{2}$, Selman Yeniocak ${ }^{1}$, Ibrahim Turan ${ }^{2}$, Oguz Eroglu ${ }^{1}$, Utku Ucar ${ }^{2}$, Yunus Karaca ${ }^{1}$, Suha Turkmen ${ }^{1}$ and Robert M Russell ${ }^{1}$

Address: ${ }^{1}$ Department of Emergency Medicine, Karadeniz Technical University Faculty of Medicine, Trabzon, Turkey, ${ }^{2}$ Department of Biochemistry, Karadeniz Technical University Faculty of Medicine, Trabzon, Turkey and ${ }^{3}$ Department of Public Health, Karadeniz Technical University Faculty of Medicine, Trabzon, Turkey

Email: Suleyman Turedi* - suleymanturedi@hotmail.com; Abdulkadir Gunduz - gunduzkadir@hotmail.com; Ahmet Mentese - ahmetmentese28@yahoo.com; Murat Topbas - murattopbas@yahoo.com; Suleyman C Karahan - sckarahan@ktu.edu.tr; Selman Yeniocak - syeniocak@hotmail.com; Ibrahim Turan - ibrturan@yahoo.com; Oguz Eroglu - erogluoguz@yahoo.com; Utku Ucar - utkuucar@hotmail.com; Yunus Karaca - yunuskaraca@hotmail.com; Suha Turkmen - suhaturkmen@mynet.com; Robert M Russell - robertrussellmd@gmail.com

* Corresponding author

Published: 30 May 2008

Respiratory Research 2008, 9:49 doi:10.1 186/1465-9921-9-49
Received: 23 November 2007

Accepted: 30 May 2008

This article is available from: http://respiratory-research.com/content/9/1/49

(C) 2008 Turedi et al; licensee BioMed Central Ltd.

This is an Open Access article distributed under the terms of the Creative Commons Attribution License (http://creativecommons.org/licenses/by/2.0), which permits unrestricted use, distribution, and reproduction in any medium, provided the original work is properly cited.

\begin{abstract}
Study objective: The primary aim of this study was to investigate whether IMA levels are helpful in the diagnosis of pulmonary embolism (PE). The secondary aim was to determine whether IMA was more effective alone or in combination with clinical probability scores in the diagnosis of PE. Thirdly, the sensitivity and specificity of IMA is compared with D-dimer both with and without clinical probability scores in patients with suspected PE.
\end{abstract}

Methods: Consecutive patients presenting to the emergency department with suspected PE were prospectively recruited, and healthy volunteers were also enrolled as controls. D-dimer and IMA levels were measured for the entire study group. Wells and Geneva scores were calculated and s-CTPA was performed on all suspected PE patients.

Results: The study population consisted of $\mathrm{I} 30$ patients with suspected PE and 59 healthy controls. Mean IMA levels were $0.362 \pm 0.1$ I ABSU for Group A, the PE group $(n=75) ; 0.265 \pm 0.07$ ABSU for Group B, the non-PE group $(n=55)$; and $0.175 \pm 0.05$ ABSU for Group $C$, the healthy control group $(p<0.000 \mathrm{I})$. At a cut-off point of 0.25 ABSU, IMA was $93 \%$ sensitive and $75 \%$ specific in the diagnosis of PE. PPV was $79.4 \%$ and NPV was $78.6 \%$. Mean D-dimer levels were $12.48 \pm 10.88 \mu \mathrm{g} / \mathrm{ml}$ for Group A; $5.36 \pm 7.80 \mu \mathrm{g} /$ $\mathrm{ml}$ for Group B and $0.36 \pm 0.16 \mu \mathrm{g} / \mathrm{ml}$ for Group $C(p<0.000 \mathrm{I})$. The D-dimer cut-off point was $0.8 \mathrm{I} \mu \mathrm{g} /$ $\mathrm{ml}$ with a sensitivity of $98.9 \%$ and a specificity of $62.7 \%$, PPV of $69.4 \%$ and NPV of $83.3 \%$. The use of IMA in combination with Wells and Geneva clinical probability scores was determined to have a positive impact on these scores' sensitivity and negative predictive values.

Conclusion: IMA is a good alternative to D-dimer in PE diagnosis in terms of both cost and efficiency. Used in combination with clinical probability scores, it has a similar positive effect on NPV and sensitivity to that of D-dimer. The PPV of IMA is better than D-dimer, but it is still unable to confirm a diagnosis of PE without additional investigation. 


\section{Introduction Background}

Pulmonary embolism (PE) is a common and potentially life-threatening disorder. Because symptoms and signs are nonspecific, the diagnosis of PE in the emergency department (ED) still poses difficulties [1].

\section{Importance}

None of the available laboratory tests are capable of reliably excluding the diagnosis, and the clinician therefore has to rely on such diagnostic techniques as lung scintigraphy, spiral computed tomographic pulmonary angiography (s-CTPA) or pulmonary angiography [2]. New and simple tests are therefore needed in order to exclude PE and to reduce the number of these sophisticated imaging techniques required.

Under acute ischemic conditions, the metal binding capacity of albumin to transition metals such as copper, nickel and cobalt is reduced, generating a metabolic variant of the protein generally referred to as ischemia modified albumin (IMA) [3]. IMA is a sensitive marker of myocardial ischemia, skeletal ischemia, mesenteric ischemia and stroke [4-7]. There is only one study in the literature regarding the diagnostic value of IMA in the diagnosis of PE [8].

\section{Objectives}

The primary aim of our study was to investigate whether IMA levels are a useful marker that can be used in the diagnosis of $\mathrm{PE}$, the secondary aim being to determine whether IMA alone or in combination with clinical probability scores can be used as an alternative to D-dimer as a laboratory marker in the diagnostic work-up of patients with suspected PE.

\section{Materials and methods Study design}

This study is a primary analysis of data collected during a prospective, observational study at a tertiary care center.

\section{Setting}

The setting was the ED of Karadeniz Technical University, Faculty of Medicine in the city of Trabzon in Turkey. Some 20,000 patients present to the ED annually.

\section{Selection of participants}

The protocol for the study was approved by the hospital's local ethical committee. Patients were included in the study if the emergency physician suspected PE. One hundred forty-seven consecutive patients presenting to the ED with suspected PE from April, 2006, to April, 2007, were prospectively recruited for the study. Additionally, fiftyseven healthy volunteers served as a reference for biochemical parameters.
Exclusion criteria were: (i) other acute ischemic diseases newly diagnosed during the ED visit in question, such as acute coronary syndrome (ACS), acute ischemic cerebrovascular disease, acute peripheral arterial occlusion, or acute mesenteric ischemia; (ii) an abnormal serum albumin level making the determination of IMA levels impossible (normal level 3,5-5,5 mg/dl); (iii) advanced liver, kidney or heart failure; (iv) troponin-T and ECG testing was performed for evidence of asymptomatic coronary ischemia; (v) age <18 years; (vi) allergy to contrast material and (vii) refusal to participate in the study. The exclusion criteria applied during the enrolment of the controlhealthy group were the same as those for the patient group. Patients were observed until discharged from the hospital or until death.

\section{Data collection and processing}

Emergency physicians completed a questionnaire consisting of details of the patient's medical history (such as risk factors). Physical examination, chest X-ray and ECG, IMA, $\mathrm{D}$-dimer and arterial blood analysis were performed for all patients, and both the simplified Well's and the Geneva scores were calculated before tomographic examination $[9,10]$.

Spiral-CTPA was performed on all patients who had no exclusion criteria. Patients were divided into two groups according to the s-CTPA results, Group A, the PE group, and Group $\mathrm{B}$, the non-PE group. The healthy control group was classified as Group C. s-CTPA was not performed in Group C although blood analysis for IMA and D-dimer was carried out.

\section{Methods of measurement IMA measurement}

Blood samples were taken from the brachial vein at time of presentation. Reduced cobalt to albumin binding capacity (IMA level) was analyzed using the rapid and colorimetric method developed by Bar-Or et al. [11]. This is based on the principle of quantitative scanning of the free cobalts present after cobalt binding has taken place. This means that high absorbance levels as a result of increased amounts of free cobalt in the environment can be determined.

\section{D-dimer measurement}

D-dimer was assayed using the quantitative, immunotubidimetric STA-Liatest D-dimer kit assay from Diagnostica Stago, Asnieres, France, which was run on an automatic coagulation analyzer (STA-compact, Diagnostica Stago) in a routine setting.

\section{CT imaging and images interpretation}

All patients underwent s-CTPA within 12 hours of selective pulmonary angiography using a 16 detector spiral CT 


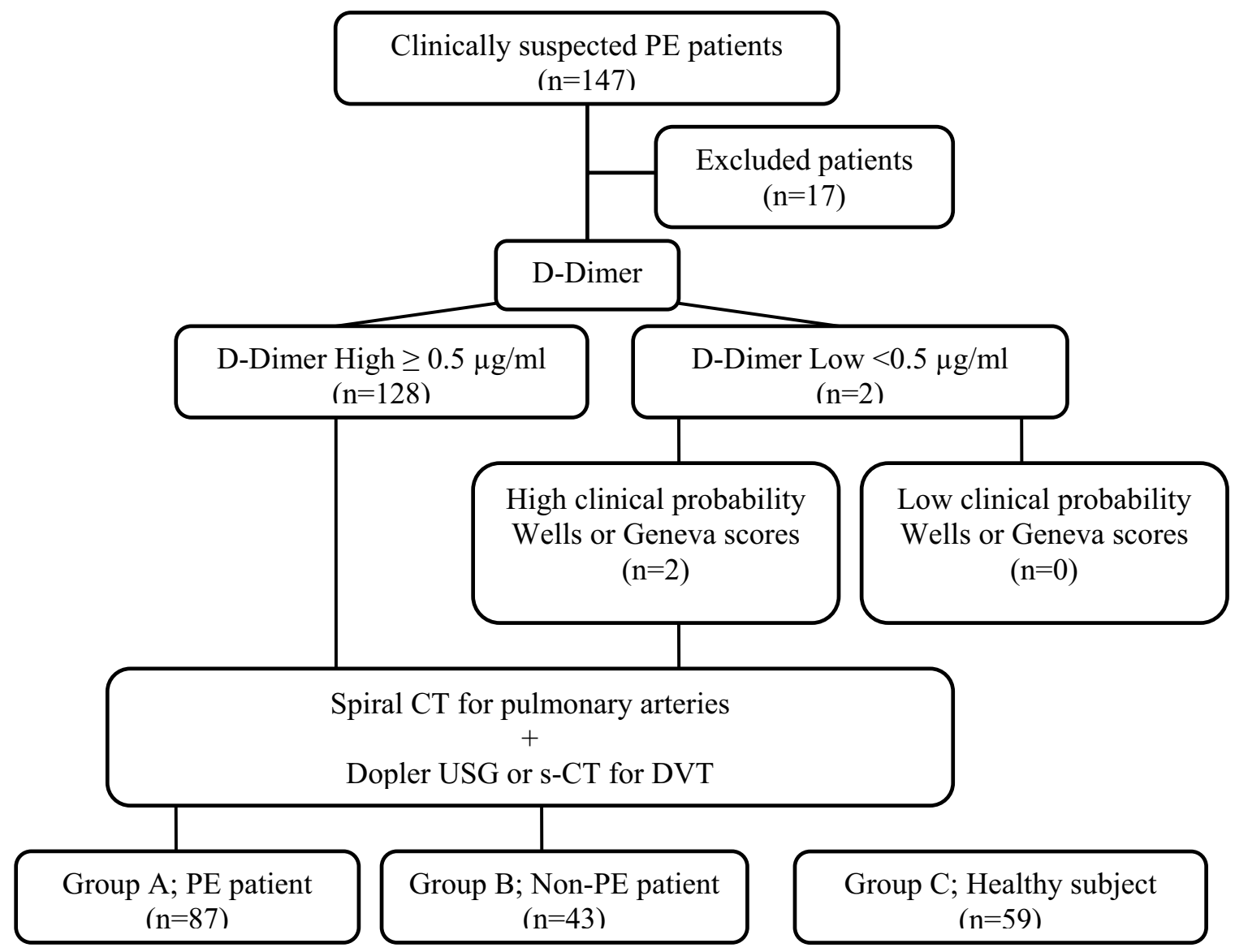

Figure I

Our diagnostic work-up in suspected PE patients.

scanner (Siemens Somatom Sensatio, Germany). CT scans were reviewed by radiologists experienced in analyzing sCTPA. The radiologists were blinded to the results of the D-dimer and IMA testing. The s-CTPA criteria used to diagnose PE consisted of direct visualization of nonocclusive endoluminal thrombus (central filling defect or partially outlined by contrast agent) or of complete occlusion by thrombus in normal-sized or enlarged vessels.

\section{Primary data analysis}

Statistical analysis was performed using the SPSS version 13.0 (SPSS, Chicago, IL, USA). For the IMA and D-dimer, the test characteristics, sensitivity, specificity, negative and positive predictive values were calculated according to the $\mathrm{s}$-CT results. The area beneath the receiver operating characteristics (ROC) curves was used to compare the discriminative power of the IMA and D-dimer tests in the diagnosis or ruling out of PE. The compatibility of the data with normal distribution was investigated using the Kolmogorov-Smirnov test. Kruskal-Wallis analysis of variance (Mann-Whitney U-test with post-hoc Bonferroni correction) was used to compare IMA and D-dimer among the groups. Statistical significance was assumed at a level of $\mathrm{P}<0.05$.

\section{Results}

\section{Characteristics of study subjects}

A total of 147 patients with suspected PE and 59 healthy control subjects were enrolled in the study. Seventeen patients were excluded because of predefined criteria: ACS $(n=7)$, acute ischemic cerebrovascular disorder $(n=1)$, paradoxical embolism $(n=1)$, advanced renal insufficiency $(n=3)$, advanced congestive heart failure $(n=1)$, peripheral arterial occlusion $(n=3)$, sepsis $(n=1)$.

All the 130 remaining suspected PE patients underwent sCTPA at the time of admission. Patients were divided into two groups, Group A, the PE group ( $\mathrm{n}=75)$, and Group $\mathrm{B}$, the non-PE group $(\mathrm{n}=55)$, according to the s-CTPA results. The healthy control group was classified as Group $C(n=59)$. Our diagnostic work-up is presented in Figure 1. 
The baseline demographic and clinical characteristics of Groups A, B and C are given in Table 1.

\section{Main results}

The serum IMA and D-dimer levels of the groups are shown in Table 2.

The D-dimer vs IMA levels were determined to be statistically different to one another in all groups $(\mathrm{p}<0.0001)$ The highest IMA and D-dimer levels were determined in Group A patients, while there was also a statistically significant difference between the levels in Groups B and C ( $\mathrm{p}<$ 0.0001 ). The receiver operating characteristic curve of IMA and D-dimer for diagnosis of PE at admission is shown in Figure 2 and 3.

The area under the curve for IMA was 0.889 (bootstrap $95 \% \mathrm{Cl}, 0,842-0,936)$. The optimum diagnostic cut-off point maximizing sensitivity and specificity was determined to be 0.25 ABSU, with a sensitivity of $93.1 \%$ and a specificity of $75.5 \%$. The corresponding PPV and NPV levels were $79.4 \%$ and $78.6 \%$, respectively. The area under the curve for D-dimer was 0.893 (bootstrap 95\% Cl, $0,845-0,941)$. The optimum diagnostic cut-off point maximizing sensitivity and specificity was determined to be $0.81(\mu \mathrm{g} / \mathrm{ml})$, with a sensitivity of $98.9 \%$ and a specificity of $62.7 \%$. The corresponding PPV and NPV levels were $69.4 \%$ and $83.3 \%$, respectively.

The scattergram of the serum IMA and D-dimer values in all groups is shown in Figure 4 and 5 .

Predictive values of negative IMA $(<0.25$ ABSU), negative D-dimer $(<0.81 \mu \mathrm{g} / \mathrm{ml}), \mathrm{CRP} \leq 0.59 \mathrm{mg} / \mathrm{dl}, \mathrm{Sa} 02 \geq 90 \%$, respiratory rate $\leq 20 / \mathrm{mi}$, heart rate $\leq 100 / \mathrm{min}$ and $\mathrm{PH}<7.45$, alone and in combination for excluding $\mathrm{PE}$ diagnosed on the basis of s-CTPA, are shown in Table 3.

Group A and B Wells and Geneva clinical probability scores were also analyzed in our study. Group C (healthy volunteers) scores were not included in this analysis, and statistical calculations were performed for Group A and B patients alone.

The receiver operating characteristic curves of Wells and Geneva scores for diagnosis of PE at admission are shown in Figure 6 and 7. According to these,; the area under the curve for the Wells score was 0.765 (bootstrap 95\% Cl, 0.681-0.849). The optimum diagnostic cut-off point maximizing sensitivity and specificity was found to be 2 points, with a sensitivity of $79.3 \%$ and a specificity of $48.8 \%$. The corresponding PPV and NPV levels were $75.8 \%$ and $53.8 \%$, respectively.
The area under the curve for the Geneva score was 0.659 (bootstrap 95\% Cl, 0.558-0.759). The optimum diagnostic cut-off point maximizing sensitivity and specificity was found to be 5 points, with a sensitivity of $73.6 \%$ and a specificity of $51.2 \%$, respectively. The corresponding PPV and NPV levels were $75.3 \%$ and $48.9 \%$, respectively.

Based on the cut-off values determined, biochemical markers and clinical probability scores were subsequently combined. Using a positive s-CTPA as the standard for diagnosis of PE, the diagnostic accuracy levels of the IMA, D-dimer, Well's score, Geneva score, Well's score + IMA, Geneva score + IMA, Well's score + D-dimer, Geneva score + D-dimer are shown in Table 4.

\section{Limitations}

Because our facility is a tertiary referral center and receives many patients who have been pre-screened by outlying hospitals and clinics, the prevalence of PE in our patients was very high. The PPV and NPV levels for the tests and criteria described may be different for populations with a different prevalence of PE.

The definitive diagnosis of PE was made using s-CTPA. The sensitivity and specificity of s-CT range from 53\% to $\% 100$ and from $81 \%$ to $100 \%$, respectively, when pulmonary arteriography is used as the standard for diagnosis of PE [12]. For that reason, subsegmental or micro-embolisms invisible under s-CTPA may be present, especially in Group B patients. Even if this is not absolutely certain, it may well account for some high IMA values determined in Group B patients.

There are no data for the period following hospital discharge, so there may have been patients in Group B who developed PE subsequently.

IMA is a new biomarker, the levels of which are significantly influenced by wide range of physiological variables, including exercise and hydration. It may also be elevated in a number of other diseases. In our patient selection, we eliminated patients with advanced liver, kidney or congestive heart failure, which can alter IMA levels. We were unable, however, to check for all variables which could possibly influence IMA levels.

\section{Discussion}

The literature contains studies regarding the use of IMA in acute ischemic conditions. It has been reported in these that IMA can be used as a diagnostic marker, especially in ACS [13-15]. IMA may not be specific for cardiac ischemia. Data concerning IMA levels in non-cardiac ischemia are limited. Some evidence suggests that IMA increases in stroke, mesenteric ischemia, end-stage renal disease, liver disease and some neoplasms [16]. 
Table I: Baseline demographic and clinical characteristics of the study population.

\begin{tabular}{|c|c|c|c|c|c|c|}
\hline \multirow{3}{*}{$\begin{array}{l}\text { Mean Age } \pm \text { SD (years) } \\
\text { Sex }\end{array}$} & \multirow{2}{*}{\multicolumn{2}{|c|}{$\begin{array}{c}\text { Group A }(n=87,46 \%) \\
68.37 \pm 11.55\end{array}$}} & \multirow{2}{*}{\multicolumn{2}{|c|}{$\begin{array}{c}\text { Group B }(n=43,22,8 \%) \\
67.30 \pm 14.94\end{array}$}} & \multirow{2}{*}{\multicolumn{2}{|c|}{$\begin{array}{c}\text { Group C }(n=59,31,2 \%) \\
62.42 \pm 10.46\end{array}$}} \\
\hline & & & & & & \\
\hline & $\mathrm{n}$ & $\%$ & $\mathrm{n}$ & $\%$ & $n$ & $\%$ \\
\hline Female & 53 & 60.9 & 20 & 46.5 & 29 & 49.1 \\
\hline Male & 34 & 39.1 & 23 & 53.5 & 30 & 50.9 \\
\hline Symptoms & $\mathrm{n}$ & $\%$ & $\mathrm{n}$ & $\%$ & & \\
\hline Cough & 27 & 31.0 & 14 & 32.6 & & \\
\hline Chest pain & 42 & 48.3 & 17 & 39.5 & & \\
\hline Dyspnea & 77 & 88.5 & 35 & 81.4 & & \\
\hline Hemoptysis & 8 & 9.2 & 4 & 9.3 & & \\
\hline Syncope & 18 & 20.7 & 5 & 11.6 & & \\
\hline Symptoms of DVT & 7 & 8.0 & 1 & 2.3 & & \\
\hline Asymptomatic & 3 & 3.4 & I & 2.3 & & \\
\hline Clinical signs & \multicolumn{2}{|c|}{ Mean \pm SD } & \multicolumn{2}{|c|}{ Mean \pm SD } & & \\
\hline Heart rate & \multicolumn{2}{|c|}{$104.74 \pm 23.56$} & \multicolumn{2}{|c|}{$103.88 \pm 23.02$} & & \\
\hline Respiratory rate & \multicolumn{2}{|c|}{$27.53 \pm 6.26$} & \multicolumn{2}{|c|}{$25.65 \pm 7.77$} & & \\
\hline Fever & \multicolumn{2}{|c|}{$36.75 \pm 0.79$} & \multicolumn{2}{|c|}{$36.92 \pm 0.78$} & & \\
\hline Systolic BP & \multicolumn{2}{|c|}{$113.39 \pm 35.57$} & \multicolumn{2}{|c|}{$122.86 \pm 28.99$} & & \\
\hline Diastolic BP & \multicolumn{2}{|c|}{$72.44 \pm 19.88$} & \multicolumn{2}{|c|}{$75.63 \pm 17.85$} & & \\
\hline Chest X-ray signs & $\mathrm{n}$ & $\%$ & $\mathrm{n}$ & $\%$ & & \\
\hline Pleural effusion & 28 & 32.2 & 21 & 48.8 & & \\
\hline Atalectasis & 26 & 29.9 & 11 & 25.6 & & \\
\hline Diaphragm elevation & 26 & 29,8 & II & 25.6 & & \\
\hline Hampton's sign & 4 & 4.6 & 0 & & & \\
\hline Westermach sign & I & 1.1 & 0 & & & \\
\hline Pulmonary artery dilatation & 10 & 11.5 & 2 & 4.7 & & \\
\hline ECG signs & $\mathrm{n}$ & $\%$ & $\mathrm{n}$ & $\%$ & & \\
\hline SIQ3T3 & 16 & 18.4 & 1 & 2.3 & & \\
\hline Sinusal tachycardia & 42 & 48.3 & 18 & 41.9 & & \\
\hline Atrial fibrillation & 14 & 16.1 & 8 & 18.6 & & \\
\hline T negativity & 9 & 10.3 & 3 & 7.0 & & \\
\hline RBBB & 2 & 2.3 & 0 & & & \\
\hline Risk factors for VTE & $\mathrm{n}$ & $\%$ & $n$ & $\%$ & & \\
\hline Previous DVT & 11 & 12.64 & 2 & 4.65 & & \\
\hline Previous PE & 4 & 4.59 & 1 & 2.32 & & \\
\hline Varicose veins & 8 & 9.19 & 2 & 4.65 & & \\
\hline Chronic venous insuffficiency & 7 & 8.04 & I & 2.32 & & \\
\hline Previous stroke & 12 & 13.79 & 4 & 9.30 & & \\
\hline COPD & 18 & 20.68 & 13 & 30.23 & & \\
\hline $\mathrm{CHF}$ & 27 & 31.03 & 20 & 46.51 & & \\
\hline Cancer & 9 & 10.34 & 2 & 4.65 & & \\
\hline Recent surgery & 22 & 25.28 & 3 & 6.97 & & \\
\hline Recent trauma & 8 & 9.19 & 1 & 2.32 & & \\
\hline Immobilization & 57 & 65.51 & 21 & 48.83 & & \\
\hline Pregnancy & 2 & 2.29 & 1 & 2.32 & & \\
\hline Post-partum period & 0 & & I & 2.32 & & \\
\hline Obesity & 10 & 11.49 & 0 & & & \\
\hline Long bone fracture & 5 & 5.74 & 0 & & & \\
\hline
\end{tabular}


Table 2: The serum IMA and D-dimer levels of the groups.

\begin{tabular}{|c|c|c|c|c|}
\hline & Group A & Group B & Group C & $P$ value \\
\hline IMA levels (ABSU) \pm SD & $0.362 \pm 0.11$ & $0.265 \pm 0.07$ & $0.175 \pm 0.05$ & 0.0001 \\
\hline D-dimer levels $(\mu \mathrm{g} / \mathrm{ml}) \pm S D$ & $12.48 \pm 10.88$ & $5.36 \pm 7.80$ & $0.36 \pm 0.16$ & 0.0001 \\
\hline
\end{tabular}

There is only one study in the literature about the use of IMA for diagnostic purposes in PE. This study, by Turedi et al., consisting of 30 patients with PE and 30 healthy individuals, demonstrated that serum IMA levels were significantly higher than those in healthy individuals in $97 \%$ of patients [8]. Despite being a limited study, this research by Turedi et al. is an indication that IMA levels might be used in the diagnosis of PE.

Various clinical probability scores and biochemical markers are currently employed in order to exclude suspected $\mathrm{PE}$ in patients without using invasive and high-cost scanning tools. The most frequently used among these biochemical markers is $\mathrm{D}$-dimer. The negative predictive value of D-dimer levels for ruling out a diagnosis of thromboembolic disease has been reported as high [17]. However, D-dimer is a rather non-specific marker and its positive predictive value is very low.

The assessment of pretest probability, allowing the categorization of patients clinically suspected of having PE into low, intermediate and high clinical probability, is an essential step in contemporary diagnostic strategies because such categorization helps determine the need for and type of additional testing in patients suspected of having pulmonary emboli [18]. The association of a low or moderate clinical probability with a normal D-dimer assay may confidently rule out PE without using imaging

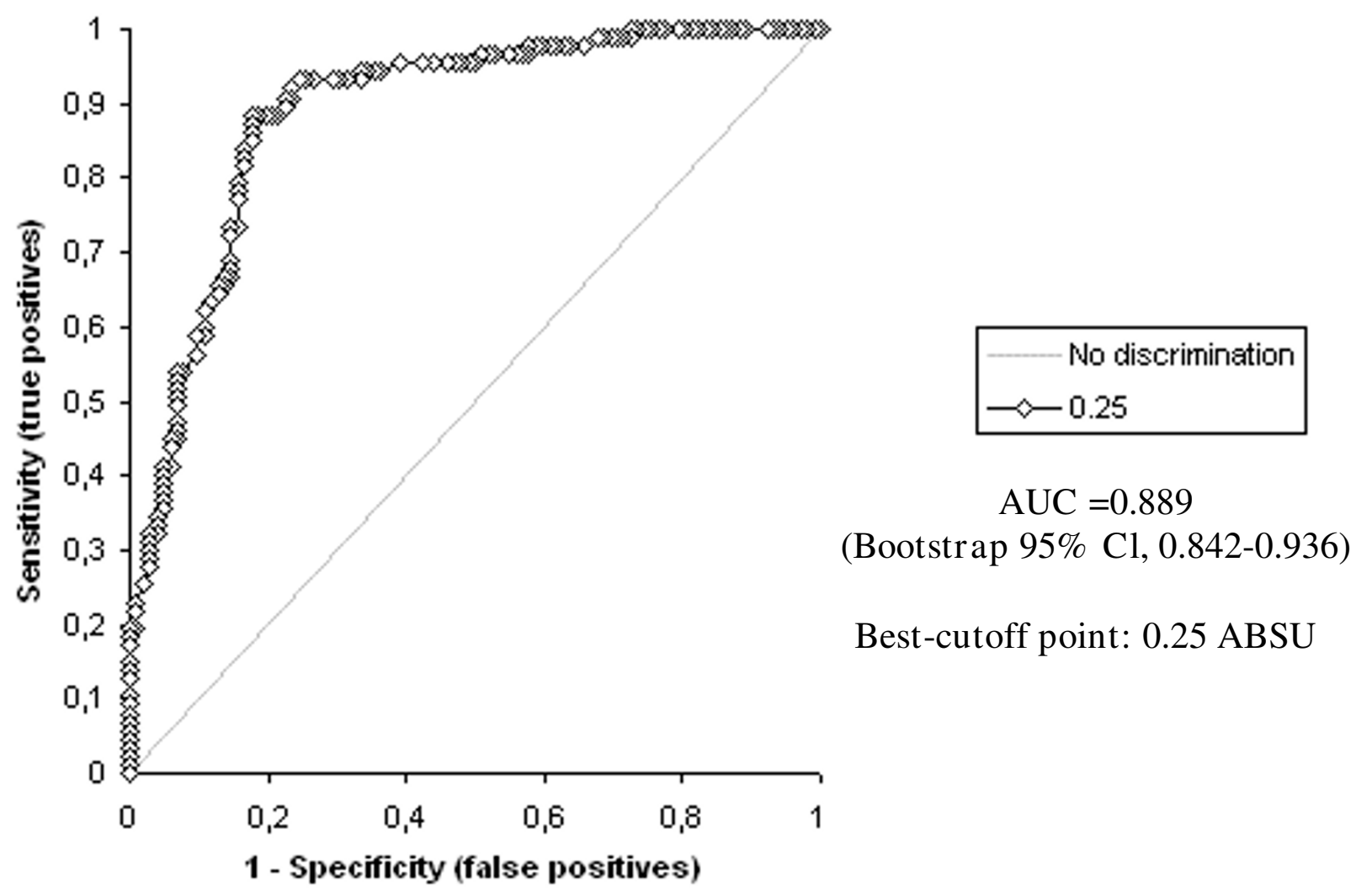

Figure 2

Receiver operating characteristics of ischemia modified albumin levels. 


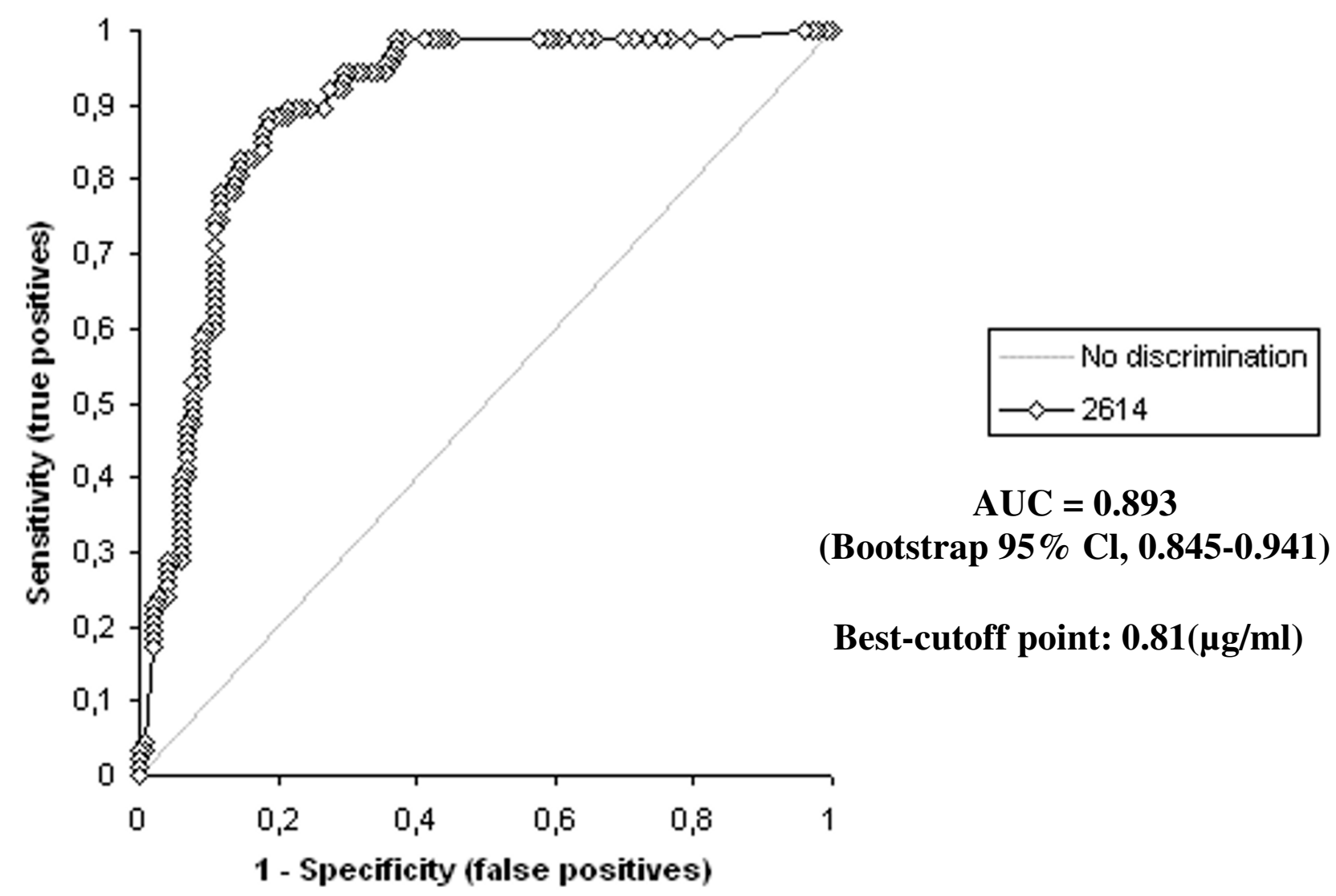

Figure 3

Receiver operating characteristics of D-dimer levels.

Table 3: Predictive value of negative IMA ( $<0.25$ ABSU), negative D-dimer $(<0.8 \mathrm{I} \mu \mathrm{g} / \mathrm{ml})$, CRP $\leq 0.59 \mathrm{mg} / \mathrm{dl}$, Sa02 $\geq 90 \%$, respiratory rate $\leq 20 / \mathrm{min}$, heart rate $\leq 100 / \mathrm{min}$ and $\mathrm{PH}<7.45$, alone and in combination for excluding PE diagnosed on the basis of s-CTPA.

\begin{tabular}{lcc}
\hline Observation & Correct exclusion & Negative predictive value \\
\hline Negative IMA $(<0.25 \mathrm{ABSU})$ & $22 / 28$ & 0.786 \\
Negative D-dimer $(<0.8 \mathrm{Ig} / \mathrm{ml})$ & $5 / 6$ & 0.883 \\
Negative CRP $(<0.59 \mathrm{mg} / \mathrm{dl})$ & $6 / 1 \mathrm{I}$ & 0.545 \\
Sa $02 \geq 90 \%$ & $30 / 89$ & 0.337 \\
Respiratory rate $\leq 20 / \mathrm{min}$ & $8 / 21$ & $0.38 \mathrm{I}$ \\
Heart rate $\leq$ I00/min, & $22 / 6 \mathrm{I}$ & $0.36 \mathrm{I}$ \\
PH<7.45 & $28 / 64$ & 0.438 \\
Negative IMA and Sa02 $\geq 90 \%$ & $15 / 20$ & 0.750 \\
Negative IMA and respiratory rate $\leq 20 /$ min & $5 / 6$ & 0.833 \\
Negative IMA and heart rate $\leq 100 /$ min, & $11 / 14$ & 0.786 \\
Negative IMA and PH $<7.45$ & $22 / 28$ & 0.786 \\
Negative IMA and negative D-dimer & $3 / 3$ & 1.00 \\
Negative IMA and negative CRP & $3 / 4$ & 0.750 \\
Negative IMA and negative D-dimer and negative CRP & $1 / 1$ & 1.00 \\
Negative IMA and Sa02 $\geq 90 \%$ and heart rate $\leq$ I00/min & $0 / 0$ & No definition
\end{tabular}




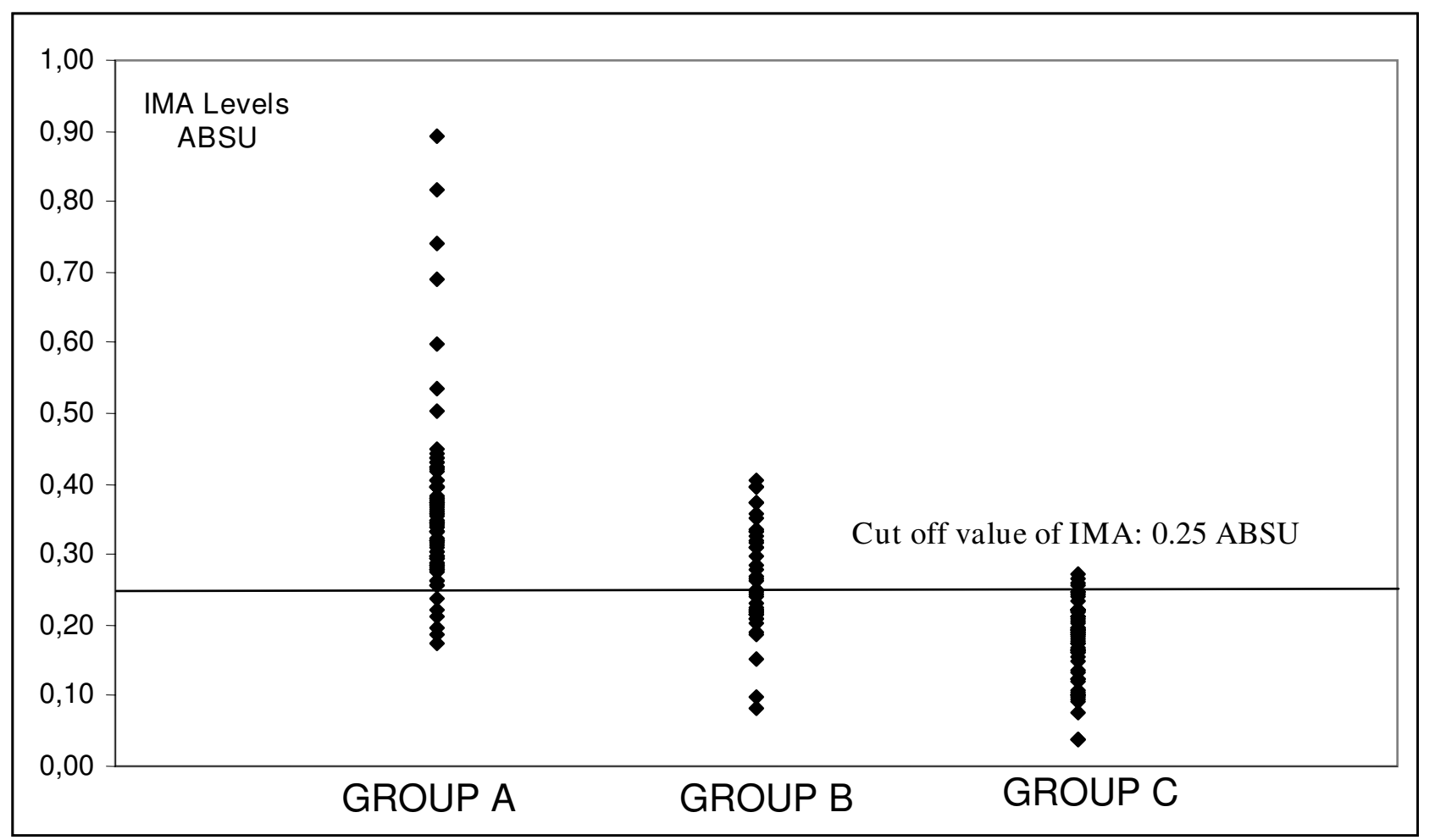

Figure 4

Scattergram of the serum IMA levels in all groups.

modalities [19]. However, in the presence of a high clinical probability, most clinicians believe that additional tests are necessary [20].

Wells et al. described a first extended score, which was rather complex and not easy to use in daily practice, and subsequently developed a simplified one [9]. The Geneva score has been described by Wicki et al. as a prediction rule [10]. It has been shown in the literature that these clinical probability scores in combination with the use of such biochemical markers as CRP and D-dimer can be useful in excluding PE [21-23]. However, the sensitivity and specificity problems associated with both probability scores and markers such as D-dimer make the identification of new, more accurate markers desirable.

In this study we investigated the diagnostic value of IMA in PE and whether or not IMA levels enhanced the diagnostic accuracy of commonly used risk stratification scales.

With a cut-off value of 0.25 ABSU, IMA sensitivity in the diagnosis of PE was $93.1 \%$, specificity was $75.5 \%$, positive predictive value was $79.4 \%$ and negative predictive value was $78.6 \%$. The PPV of a positive IMA is better than the
PPV of a positive D-dimer in the diagnosis of PE. D-dimer sensitivity and NPV have been demonstrated to be better than that of IMA and NPV. However, the results for IMA are very close to those for D-dimer and suggest that it can be used as an alternative marker. Used together with clinical probability scores it has a similarly positive effect on NPV and sensitivity to that of D-dimer. In addition IMA is a rapid and low-cost technique. Compared with D-dimer, the costs involved are some 100-200 times lower. In order to reduce patient exposure to radiation and lengthy and high-cost radiological tests, there is a need for economical and high-accuracy markers. Although it cannot be said, on the basis of the results of our study, that IMA is superior to D-dimer for that purpose, it may still be regarded as an alternative to D-dimer in terms of cost and the results determined. More comprehensive studies now need to be carried out on this subject.

In conclusion, IMA is a good alternative to D-dimer in the exclusion of PE diagnosis in terms of cost and efficiency. When used in combination with clinical probability scores, it has a similar positive effect on sensitivity to that of D-dimer and a superior one to that of NPV. 


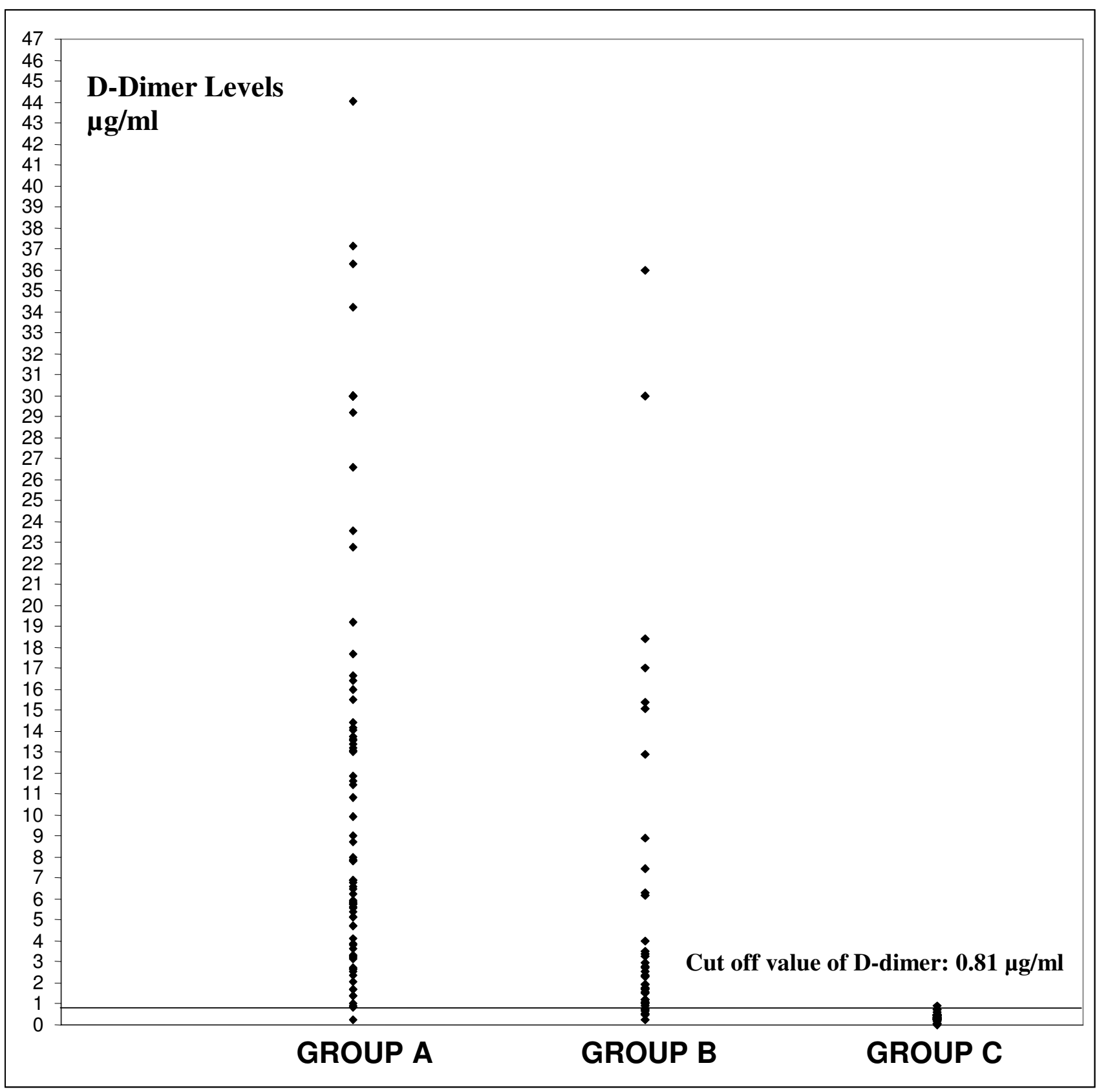

Figure 5

Scattergram of the serum D-dimer levels in all groups.

The PPV of IMA is better than D-dimer but is still unable to rule out a diagnosis of PE without additional studies. Wider-ranging studies in the future may mean that IMA becomes an important marker in the diagnostic approach to PE.

\section{Abbreviations}

IMA: ischemia-modified albumin; PE: pulmonary embolism; ED: emergency department; s-CTPA: spiral computed tomographic pulmonary angiography; ABSU: absorbance units; PPV: positive predictive value; NPV: 


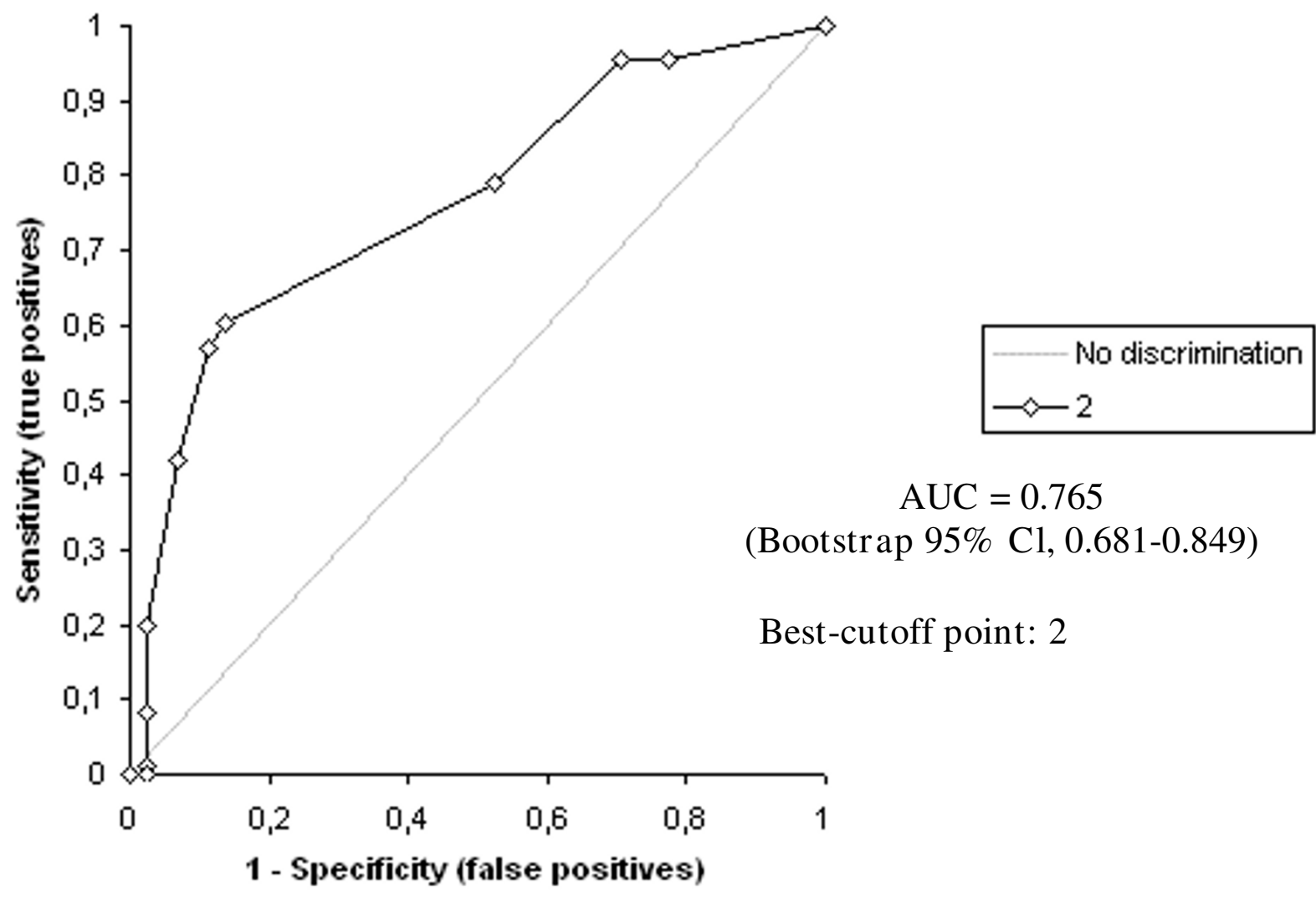

Figure 6

Receiver operating characteristics (ROC) curve of Wells score.

negative predictive value; ACS: acute coronary syndrome; ECG: electrocardiography; DTT: dithiotheitol; SPSS: statistical package for the social sciences; ROC: receiver operating characteristics; DVT: deep vein thrombosis; SD: standard deviation; BP: blood pressure; RBBB: right bundle brunch block; VTE: venous thromboembolism; COPD: chronic obstructive pulmonary disease; CHF: con- gestive heart failure; AUC: area under the curve; CRP: Creactive protein; Sa02: oxygen saturation.

\section{Authors' contributions}

ST conceived the study, designed the trial, supervised the conduct of the trial and reviewed the literature. AG conceived the study, designed the trial, supervised the conduct of the trial and reviewed the literature. AM supervised

Table 4: Performance characteristics of the Wells score, Geneva score, Well's score + IMA and Geneva score + IMA using the cutoff point of pretest probability, based on s-CTPA as reference standard.

\begin{tabular}{|c|c|c|c|c|}
\hline Score/IMA & Sensitivity $(95 \% \mathrm{Cl})$ & Specificity $(95 \% \mathrm{Cl})$ & PPV $(95 \% \mathrm{Cl})$ & NPV $(95 \% \mathrm{Cl})$ \\
\hline IMA (cutoff 0.25 ABSU) & 93.1 & 52.2 & 79.4 & 78.6 \\
\hline D-dimer (cutoff $0.8 \mathrm{I} \mu \mathrm{g} / \mathrm{ml}$ ) & 98.9 & 11.6 & 69.4 & 83.3 \\
\hline Wells score (cutoff 2 point) & 79.3 & 48.8 & 75.8 & 53.8 \\
\hline Geneva score (cutoff 5 point) & 73.6 & 51.2 & 75.3 & 48.9 \\
\hline Wells score and IMA & 97.7 & 23.3 & 72.0 & 83.3 \\
\hline Geneva score and IMA & 97.7 & 20.9 & 71.4 & 81.8 \\
\hline Wells score and D-dimer & 100.0 & 2.3 & 67.4 & 100.0 \\
\hline Geneva score and D-dimer & 100.0 & 4.7 & 68.0 & 100.0 \\
\hline
\end{tabular}




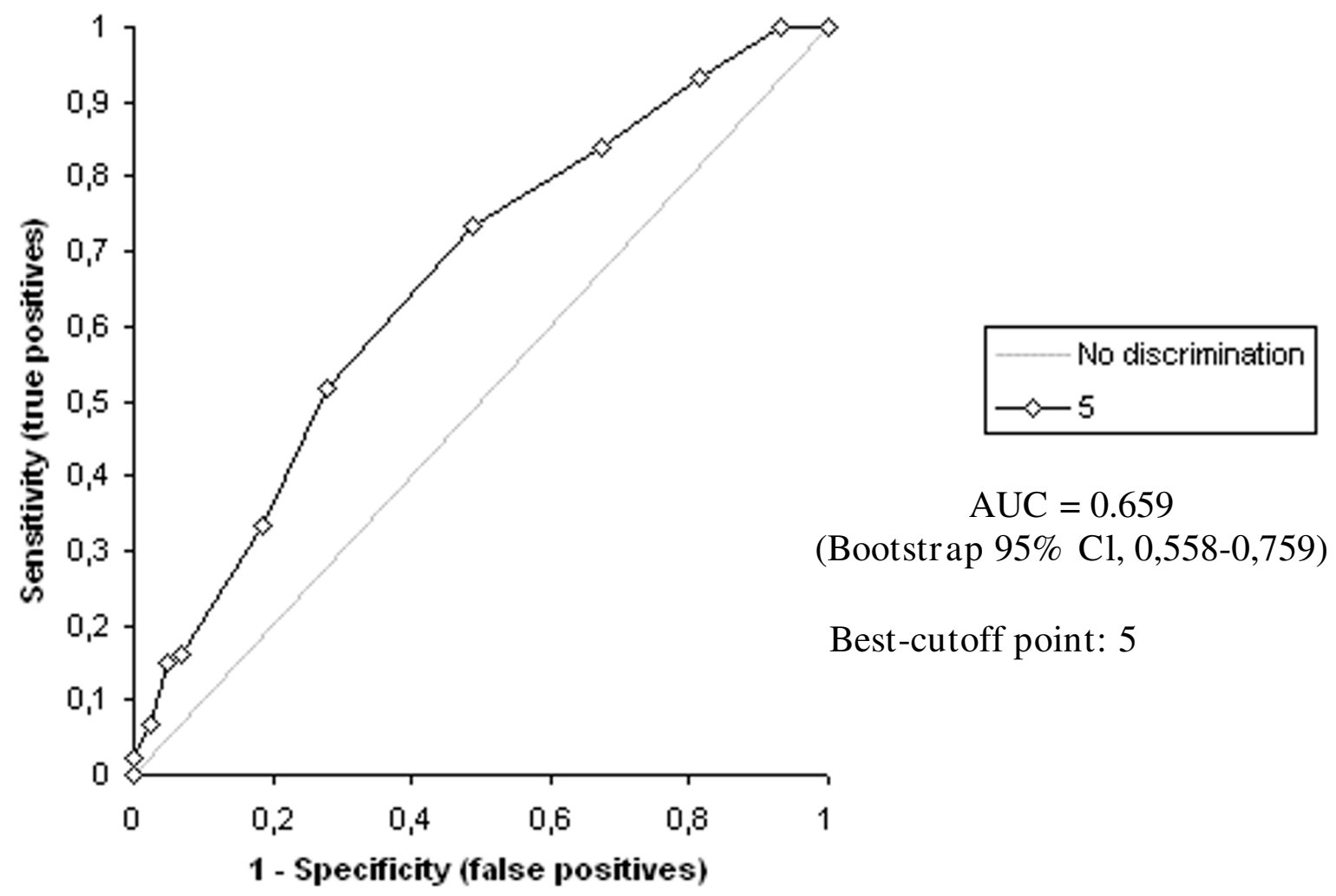

Figure 7

Receiver operating characteristics (ROC) curve of Geneva score.

the biochemical data collection and analyzed of these data. MT provided statistical advice on study design and analyzed the data. SCK supervised the conduct of the trial and biochemical data collection. SY in the collection, analysis, and interpretation of data. IT analyzed the biochemical data. OE in the collection, analysis, and interpretation of data. UU analyzed the biochemical data. YK in the collection, analysis, and interpretation of data. ST in the collection, analysis, and interpretation of data. RMR in the writing of the manuscript.

\section{References}

I. Palla A, Giuntini C: Diagnosis of pulmonary embolism: have we reached our goal? Respiration 2004, 71:22-3.

2. Nilsson T, Söderberg M, Lundqvist G, Cederlund K, Larsen F, Rasmussen E, Svane B, Brohult J, Johnsson $\mathrm{H}$ : A comparison of spiral computed tomography and latex agglutination D-dimer assay in acute pulmonary embolism using pulmonary arteriography as gold standard. Scand Cardiovasc J 2002, 36:373-7.

3. Dusek J, St'ásek J, Tichý M, Bis J, Gregor J, Vojácek J, Masín V, Polanský $\mathrm{P}$, Brtko M, Cernohorský D: Prognostic significance of ischemia modified albumin after percutaneous coronary intervention. Clin Chim Acta 2006, 367:77-80.

4. Abboud H, Labreuche J, Meseguer E, Lavallee PC, Simon O, Olivot JM, Mazighi M, Dehoux M, Benessiano J, Steg PG, Amarenco P: Ischemia-modified albumin in acute stroke. Cerebrovasc Dis 2007, 23:216-20.
5. Lippi G, Montagnana M, Guidi GC: Albumin cobalt binding and ischemia modified albumin generation: an endogenous response to ischemia? Int I Cardiol 2006, 108:4I0-I.

6. Refaai MA, Wright RW, Parvin CA, Gronowski AM, Scott MG, Eby CS: Ischemia-modified albumin increases after skeletal muscle ischemia during arthroscopic knee surgery. Clin Chim Acta 2006, 366:264-8.

7. Gunduz A, Turedi S, Mentese A, Karahan SC, Hos G, Tatli O, Turan I, Ucar U, Russell RM, Topbas M: Ischemia-modified albumin in the diagnosis of acute mesenteric ischemia: a preliminary study. Am J Emerg Med 2008, 26(2):202-5.

8. Turedi S, Gunduz A, Mentese A, Karahan SC, Yilmaz SE, Eroglu O, Nuhoglu I, Turan I, Topbas M: The value of ischemia-modified albumin in the diagnosis of pulmonary embolism. Am J Emerg Med 2007, 25(7):770-3.

9. Wells PS, Anderson DR, Rodger M, Ginsberg JS, Kearon C, Gent M, Turpie AG, Bormanis J, Weitz J, Chamberlain M, Bowie D, Barnes D, Hirsh J: Derivation of a simple clinical model to categorize patients probability of pulmonary embolism: increasing the models utility with the SimpliRED D-dimer. Thromb Haemost 2000, 83:416-20.

10. Wicki J, Perneger TV, Junod AF, Bounameaux H, Perrier A: Assessing clinical probability of pulmonary embolism in the emergency ward: a simple score. Arch Intern Med 2001, 161:92-7.

II. Bar-Or D, Lau E, Winkler JV: A novel assay for cobalt-albumin binding and its potential as a marker for myocardial ischemia-a preliminary report. J Emerg Med 2000, 19:3 I I-5.

12. Perrier A: Noninvasive diagnosis of pulmonary embolism. Haematologica 1997, 82:328-331.

13. Cho DK, Choi JO, Kim SH, Choi J, Rhee I, Ki CS, Lee SC, Gwon HC: Ischemia-modified albumin is a highly sensitive serum marker of transient myocardial ischemia induced by coronary vasospasm. Coron Artery Dis 2007, 18:83-7. 
14. Keating L, Benger JR, Beetham R, Bateman S, Veysey S, Kendall J, Pullinger R: The PRIMA study: presentation ischaemia-modified albumin in the emergency department. Emerg Med J 2006, 23:764-8.

15. Bhagavan NV, Lai EM, Rios PA, Yang J, Ortega-Lopez AM, Shinoda H, Honda SA, Rios CN, Sugiyama CE, Ha CE: Evaluation of human serum albumin cobalt binding assay for the assessment of myocardial ischemia and myocardial infarction. Clin Chem 2003, 49:58I-5.

16. Apple FS, Wu AH, Mair J, Ravkilde J, Panteghini M, Tate J, Pagani F, Christenson RH, Mockel M, Danne O, Jaffe AS, Committee on Standardization of Markers of Cardiac Damage of the IFCC: Future biomarkers for detection of ischemia and risk stratification in acute coronary syndrome. Clin Chem 2005, 51:810-24.

17. Perrier A, Desmarais S, Miron MJ, de Moerloose P, Lepage R, Slosman $D$, Didier D, Unger PF, Patenaude JV, Bounameaux H: Non-invasive diagnosis of venous thromboembolism in outpatients. Lancet 1999, 353:190-5.

18. Righini M, Bounameaux $\mathrm{H}$ : External validation and comparison of recently described prediction rules for suspected pulmonary embolism. Curr Opin Pulm Med 2004, 10:345-9.

19. Perrier A, Roy PM, Aujesky D, Chagnon I, Howarth N, Gourdier AL, Leftheriotis G, Barghouth G, Cornuz J, Hayoz D, Bounameaux H: Diagnosing pulmonary embolism in outpatients with clinical assessment, D-dimer measurement, venous ultrasound, and helical computed tomography: a multicenter management study. Am J Med 2004, I I 6:291-9.

20. Kruip MJ, Slob MJ, Schijen JH, Heul C van der, Büller HR: Use of a clinical decision rule in combination with D-dimer concentration in diagnostic workup of patients with suspected pulmonary embolism: a prospective management study. Arch Intern Med 2002, 162:1631-5.

21. Steeghs N, Goekoop RJ, Niessen RW, Jonkers GJ, Dik H, Huisman $M V$ : C-reactive protein and D-dimer with clinical probability score in the exclusion of pulmonary embolism. Br J Haematol 2005, I30:6 I4-9.

22. Burkill GJ, Bell JR, Chinn RJ, Healy JC, Costello C, Acton L, Padley SP: The use of a D-dimer assay in patients undergoing CT pulmonary angiography for suspected pulmonary embolus. Clin Radiol 2002, 57:4I-6.

23. Goekoop RJ, Steeghs N, Niessen RW, Jonkers GJ, Dik H, Castel A, Werker-van Gelder L, Vlasveld LT, van Klink RC, Planken EV, Huisman MV: Simple and safe exclusion of pulmonary embolism in outpatients using quantitative D-dimer and Wells simplified decision rule. Thromb Haemost 2007, 97: 146-50.

Publish with Bio Med Central and every scientist can read your work free of charge

"BioMed Central will be the most significant development for disseminating the results of biomedical research in our lifetime. "

Sir Paul Nurse, Cancer Research UK

Your research papers will be:

- available free of charge to the entire biomedical community

- peer reviewed and published immediately upon acceptance

- cited in PubMed and archived on PubMed Central

- yours - you keep the copyright

Submit your manuscript here:

http://www.biomedcentral.com/info/publishing_adv.asp
BiolMedcentral 